\title{
Low-Income Consumers and Payment Choice
}

\section{Oz Shy}

\section{Working Paper 2020-03a \\ February 2020 (revised October 2020)}

\begin{abstract}
Low-income consumers are not only constrained with spending but also with the type and variety of payment methods available to them. Using a representative sample of the U.S. adult population, this short paper analyzes the low possession (adoption) of credit and debit cards among low-income consumers who are also unbanked. Using a random utility model, I simulate the potential consumer welfare gains associated with policy options suggested in the literature to provide unsubsidized or subsidized debit cards, or subsidized prepaid cards to this consumer population. Simulation results show the relative improvement in consumer welfare among all three policy options.
\end{abstract}

JEL classification: D9, E42

Key words: consumer payment choice, household income, financial inclusion, unbanked consumers https://doi.org/10.29338/wp2020-03a

The author thanks Larry Wall for comments on an earlier draft. The views expressed here are those of the author and not necessarily those of the Federal Reserve Bank of Atlanta or the Federal Reserve System. Any remaining errors are the author's responsibility.

Please address questions regarding content to 0z Shy, Research Department, Federal Reserve Bank of Atlanta, 1000 Peachtree St. NE, Atlanta, GA 30309, oz.shy@atl.frb.org.

Federal Reserve Bank of Atlanta working papers, including revised versions, are available on the Atlanta Fed's website at www.frbatlanta.org. Click "Publications" and then "Working Papers." To receive e-mail notifications about new papers, use frbatlanta.org/forms/subscribe. 


\section{Introduction}

Payments for purchases of goods and services and bill payments are made with the use of payment instruments such as cash, checks, credit cards, debit cards, prepaid cards, and account-to-account money transfers. However, as shown in this article, low-income consumers tend to have a lower variety of payment methods, and a smaller fraction of them own a bank account relative to highincome consumers. Therefore, low-income consumers are not only constrained with spending, but also with the type and variety of payment methods available to them.

This short article has two goals: First, to investigate the strong correlation between household income and the ownership of credit cards, debit cards, and bank accounts. Second, to analyze some policy proposals that have been discussed in the literature regarding the provision of unsubsidized and subsidized debit cards to unbanked consumers who rely mainly on cash to make payments. I also analyze the effect of subsidizing the cost of prepaid cards.

The motivation behind these policies stems from the fact that innovations in payment technologies do not always apply to some segments of the population. In particular the introduction of cashless stores and mobile apps cannot benefit consumers who do not have credit and debit cards. That also apply to online shopping which requires the use of credit and debit cards.

Both goals are accomplished with the use of a representative sample of the U.S. adult population. This sample contains information on bank account ownership, availability of credit and debit cards, individual assessments of each payment instrument, household income, and other demographic variables. In addition, the sample records actual payments made by the respondents including payment dollar amount, payment method, and merchant type.

The policy analysis is accomplished with the use of simulations based on utility estimates generated by a random utility model. Note that the utility derived from paying with a certain payment instrument is different from the utility derived from consuming the product or service for which the payment is made. It is the utility (or disutility) derived from the process of having to pay with a particular payment instrument. This utility is computed by regressing individu-

als' payment choice at the point of sale on individuals' assessments of cost, security, and convenience of each payment instrument. The simulations of policy options recompute the utility after 
unsubsidized and subsidized debit cards are added to the set of available payment methods of unbanked consumers, and also under the hypothetical policy of providing a cost subsidy to prepaid card users. Simulation results show the relative improvement in consumer welfare among all three policy options.

In the literature, several papers experimented with measuring the welfare consequences of adding/subtracting a payment instrument to/from the set of existing payment methods. Alvarez and Argente (2019) estimate the utility loss from only accepting cards for Uber rides, based on data from Mexico. Briglevics and Schuh (2020) use data from the 2012 Diary and Survey of Consumer Payment Choice to quantify utility losses with removing payment choices for U.S. consumers. Shy (2020) analyzes the consequences of stores becoming cashless. Huynh et al. (2020) and Wakamori and Welte (2017) use data from Canada where access to bank accounts is nearly universal. Huynh et al. (2020) introduce a central bank digital currency in which they assume to combine the most favorable features of cash, debit card, and credit card and compute the utility gains for consumers. Wakamori and Welte (2017) construct a policy experiment where all merchants accept all payment methods, based on a supposition that the government regulates card merchant fees to a very low level.

This article is organized as follows. Section 2 characterizes banked and unbanked consumers' possession of credit or debit cards belonging to different household income groups. Section 3 develops the method for measuring the per-payment benefit and cost of using each payment method. Section 4 provides simulations of the welfare effects associated with several policy proposals directed toward unbanked consumers that have been discussed in the literature. Section 5 provides a discussion of unbanked consumers.

\section{Household income and payment methods}

This section analyzes the correlation between household income and the type and variety of payment instruments that consumers own. 


\subsection{Data}

The data are taken from the 2017, 2018, and 2019 Survey and Diary of Consumer Payment Choice (SCPC and DCPC). ${ }^{1}$ Both, the SCPC and the DCPC, are representative samples of U.S. (18 and older) consumers. The DCPC records transactions during three consecutive days. Transactions include purchases, bill payments, ATM withdrawals and deposits. Respondents' three day diaries were evenly distributed throughout the months of October 2017, October 2018 and October 2019. In order to balance unwanted heterogeneity in response quality across days due to diary fatigue, every individual day in October had an approximately equal mix of diarists completing their first, second, and third diary days.

The number of respondents who participated in the 2017 diary is 2498, 2574 participated in 2018, and 2687 in 2019. The number of respondents who participated in both the 2017 and 2018 diaries is 1883, 1759 respondents participated in both the 2017 and 2019, and 1527 participated in all three years. Therefore, the combined sample has 3675 unique respondents. Depending on the type of analysis, respondents with missing values were excluded from the sample that was used for that analysis. All tables and charts in this article indicate the number of respondents included in the analysis.

Both, the SCPC and the DCPC have a large number of variables describing all sorts of demographics and transactions. For the purpose of this article, I focus only on a subset of variables, some of them are described below. From the SCPC, I use assessment variables where consumers rate on the scale of 1 to 5 key features of each payment instrument, such as cost, security, and convenience. I also use four binary variables "cc_adopt", "dc_adopt", "svc_adopt", and "bnk_acnt_adopt" indicating whether the respondent has a credit card, debit card, prepaid (storevalue) card, and a bank account, respectively.

Most of the variables are taken from the DCPC which records actual transactions. I restrict the analysis to payments made using the five major payment methods (pi $=1$ to 5): "cash,"

\footnotetext{
${ }^{1}$ The survey and the diary are conducted in collaboration of the Federal Reserve Banks of Atlanta, Boston, Richmond, and San Francisco. The data and assisting documents (codebooks) are publicly available for downloading from the Federal Reserve Bank of Atlanta Website: https://www.frbatlanta.org/banking-and-payments/consumer-payments. aspx. The data and the R-code used in this analysis are available for downloading from the author's Webpage: www. ozshy.com.
} 
"check," "credit card," "debit card," and "prepaid card." Other variables used include "amnt" (dollar amount of each payment), "age," "income_hh" (household income), "hh_size" (number of persons in the household), "work," "gender," and "education."

The data contain weights for all respondents that can be used to match the data with the adult U.S. population (18 and older). I indicate when the reported statistics are computed with weights either by (weighted) or (w) inside tables.

\subsection{Who doesn't have a card? Card ownership and household income}

This section identifies which payment instruments were available to survey respondents. These consumers are then grouped into card adoption (and nonadoption) profiles and according to whether they had a bank account. Note that by card adoption (equivalently, possession or ownership) I refer to credit and debit cards only and not to prepaid cards. This is because prepaid cards can always be purchased with cash at most retail and pharmacy stores and are therefore accessible to all consumers.

Figure 1 displays the shares of consumers who have both credit and debit cards, no credit card (but may have debit cards), no debit card (but may have credit cards), and none (no credit and no debit cards), as functions of their household income. Table 1 provides additional information by separating banked from unbanked consumers who do not have credit or debit cards. Table 1 is divided into columns according to respondents' household income group. The first row shows that 66.1 percent of all respondents have both credit and debit cards. However, this percentage varies widely and monotonically among the income groups: from 31.1 percent of the lowest income group all the way up to 82.5 percent of the highest income group.

The second row in Table 1 shows that the percentage of consumers with no credit cards declines sharply with income from 37.5 percent in the lowest income group down to 1.9 percent in the highest income group. This is not surprising given the fact that credit card issuers use household income and credit scores as their main criteria for issuing credit cards to consumers. The third row shows that the percentage of respondents with no debit cards does not vary much with household income.

The fourth row in Table 1 shows that consumers who have bank accounts but no credit or debit 
cards account for only 0.6 percent of all respondents. They will not be analyzed because they have the option of getting a debit card, but for some reason chose not to have it. The fifth row shows that the percentage of unbanked respondents with no cards varies significantly with household income: from 14.7 percent in the lowest income group down to zero percent in the highest income group. On average, the percentage of unbanked respondents with no cards is 3.4 percent. This is slightly lower than the number of unbanked adults reported in FDIC (2018). ${ }^{2}$ Hayashi and Minhas (2018) analyze which household characteristics beyond income are also associated with household's probability of being unbanked.

\section{Measuring consumers' benefit and cost of different payment methods}

In order to measure the effectiveness of any policy directed towards unbanked consumers who do not have credit or debit cards, there is a need to perform some estimations of consumer surplus. Therefore, the analysis in this section serves as a preparation for the welfare simulations conducted in section 4 by constructing a random utility model based on consumer cost and benefit associated with paying and using each payment method.

\subsection{Respondents' ratings of payment instruments}

Discrete choice estimations of the utility that consumers derive from a given a set of alternatives rely on known prices that consumers pay for choosing each alternative. For example, random utility models of commuters' choice among transportation modes (bus, car, subway, train, or air) are based ticket prices (fares) and travel time that passengers endure using each transportation mode.

In contrast, researchers who study consumer payment choice are unable to figure out the exact price or cost of paying with each payment instrument. There are two reasons for that: First, the profession still lacks accounting standards with respect to the separation of variable from fixed costs associated with adopting and using a particular payment instrument. For example, the cost

\footnotetext{
${ }^{2}$ FDIC (2018) reports that approximately 14.1 million over the age of 16 and older were unbanked in June 2017. In contrast, the diary collects data from adults age 18 and older. To reconcile these two definitions of adults, I divide 14.1 million by 18 and multiply by 16 to obtain approximately 12.5 million unbanked adults. Dividing by the 2017 U.S. adult population of 252.6 million yields 4.9 percent of unbanked adults. The U.S. adult population was obtained from https://datacenter.kidscount.org/.
} 
of paying cash is heavily influenced by ATM fees and their nearest location. Similarly, the cost of paying with prepaid cards depends heavily on the cost of reloading funds onto the cards. ${ }^{3}$

Second, some costs of payment instruments vary among consumers. In other words, the cost of using a particular payment method tends to be consumer specific. Consumer cost of paying with credit cards depends on whether the consumer is a borrower or a convenience user (who may also earn cash back). The cost of using debit cards depends on checking account maintenance fees charged by the card issuing bank.

For these reasons, following Koulayev et al. (2016), Huynh et al. (2020) and Shy (2020), the analysis in this article uses respondent-specific assessments of each payment instrument to identify consumer-specific cost and benefit that consumers derive from using each payment instrument. ${ }^{4}$

Table 2 shows that $78.6(67.7+10.9)$ percent of the respondents assess cash to be a low payment instrument. Also, $73.7(45.8+27.9)$ percent of the respondents assess debit cards to be a low cost payment instrument. Note that respondents' ratings 1 to 5 are not ranking in the sense that more than one payment method can be assessed as a low cost. In other words, each assessment can take any number between 1 to 5 independently of the assessment ratings assigned to other payment instruments. Examining the "Median" column in Table 2, the median rating of the cost of cash is 1, followed by debit card and check 2, then by prepaid and credit cards 3 .

The other two assessments used in this analysis are security and convenience. The column labeled Median in Table 2 shows that credit cards are viewed as slightly more secure than other payment methods. The bottom four rows show that debit and credit cards are viewed as slightly more convenient than cash and prepaid cards, and checks as the least convenient.

In order to mitigate potential endogeneity issues that may arise in the random utility regression analysis, the welfare simulations in the next section use median assessment ratings as inde-

\footnotetext{
${ }^{3}$ For payment instruments' cost studies see: Schmiedel, Kostova, and Ruttenberg (2012), Krüger and Seitz (2014), Kosse et al. (2017), and references therein. Hayashi and Keeton (2012) and Shampine (2012) compare several payment cost studies and highlight the need for developing standards for cost estimation to facilitate comparisons across time and countries.

${ }^{4}$ Klee (2008) uses transaction time (ring time) in a multinomial logit payment choice model using scanner data from grocery stores where transaction time can be measured. Borzekowski and Kiser (2008) use three attributes: checkout time, whether the payment instrument is electronic, and whether it draws funds from a liquid account. Ching and Hayashi (2010) regress on 11 consumer-perceived attributes of each payment method. Arango, Huynh, and Sabetti (2015) regress on an index that combines perceptions of costs, acceptance, record keeping, ease of use, and risk of financial loss.
} 
pendent variables. These issues may stem from the fact that assessments are subjective and may therefore affect the levels of the estimated coefficients. Using median assessment levels instead of individual-specific assessments mitigates the potential endogeneity problem because median levels may reflect the true objective features of each payment method. Table 2 displays respondents' median assessment levels of the five main payment methods. The medians are weighted by the sample's population weights.

\subsection{Using assessments to estimate consumer utility from payment methods}

This section constructs a random utility model as a preparation for section 4 that simulates the welfare consequences of making debit cards or subsidized prepaid cards (both with funding options) available to unbanked consumers. This section computes consumers' utility derived from each payment associated with the use of each payment method.

Consumers choose among five payment instruments $i=1,2,3,4,5$, where 1 denotes cash, 2 denotes check, 3 denotes credit card, 4 denotes debit card, and 5 denotes prepaid card. In a random utility model, the utility derived by respondent $n$ from paying with payment instrument $i$ for transaction $t$ is defined by

$$
\begin{aligned}
U_{n, i, t} & =V_{i}+\epsilon_{n, i, t}, \quad \text { where } \\
V_{i} & =\beta_{C} \text { cost }_{i}+\beta_{S} \text { security }_{i}+\beta_{E} \text { convenience }_{i} .
\end{aligned}
$$

$\epsilon_{n, i, t}$ is the random component of the utility (1) which is assumed to be distributed Type I Extreme Value. The independent variables $\operatorname{cost}_{i}$, security $_{i}$, and convenience $i$ are the population weighted medians of cost, security, and convenience assessments of each payment method $i=1,2,3,4,5$. The median assessment levels are displayed in Table 2. The coefficients $\beta_{C}, \beta_{S}$, and $\beta_{E}$ and their standard errors estimated from the regression model (2) are given in the estimated equation ${ }^{5}$

$$
V_{i}=\underset{0.01492}{-(0.99886) \operatorname{cost}_{i}}+\underset{0.02430}{(0.87976) \text { security }_{i}}+\underset{0.01492}{(0.99198)} \text { convenience }_{i} .
$$

The estimation is based on 20,982 payment observations made by 2,494 respondents who have

\footnotetext{
${ }^{5}$ The estimation used the mlogit R-package. All three coefficients are statistically significant at the 0.1 percent level.
} 
(adopt) both credit and debit cards. Only this group of respondents were able to choose from the entire set of payment methods. Therefore, regressing on this group is needed in order to obtain good estimates of the three coefficients $\beta_{C}, \beta_{S}$, and $\beta_{E}$ in the regression model (2). Of the 20,982 payments, 6147 were made cash (29.3 percent), 1431 with checks (6.8 percent), 5878 with credit cards (28 percent), 7142 with debit cards (34 percent), and 384 with prepaid cards (1.8 percent).

The estimated equation (3) shows that utility of paying declines with the cost of the payment instrument, $\beta_{C}<0$. In addition, $\beta_{S}>0$ and $\beta_{E}>0$ imply the utility of paying increases with the security and convenience of the payment instrument.

\section{Unbanked consumers: Consumer welfare simulations}

The estimated coefficients given in (3) are now used to simulate changes in welfare of consumers who do not have credit and debit cards. More precisely, this section investigates some policy measures that have been suggested in the literature dealing with financial inclusions of unbanked consumers with no credit or debit cards. This investigation is accomplished by computing and comparing consumer surplus before and after the hypothetical policy measure is implemented.

\subsection{Policy proposals and the problem of funding}

Perhaps, the simplest policy intervention discussed in the literature is making debit cards accessible to unbanked and consumers. On this line, Rogoff (2016) (pp. 98-100) explores the possibility of introducing subsidized debit cards. These cards could also be issued with a mobile device option. ${ }^{6}$

It must be emphasized, however, that merely giving payment cards (or mobile apps) to people is not a complete solution because a solution to the problem of how to fund these cards must be an integral part of the policy implementation. In particular, if the consumer is unbanked, the consumer can fund the card only with the use of cash (except for direct deposit of income). That is, a complete solution must also specify whether such cards will be linked to (and funded by) a commercial bank account or a government-provided (or behalf of the government) bank account, and whether these accounts maintain 100-percent reserves in order to eliminate any risk. On this

\footnotetext{
${ }^{6}$ Merchants' interchange fees on debit cards in the U.S. are substantially lower than credit card fees, see https:// www.federalreserve.gov/paymentsystems/regii-average-interchange-fee.htm and Hayashi and Minhas (2020).
} 
line, Baradaran (2015) advocates reenlisting the U.S. Post Office in its historic function of providing basic bank services. If Baradaran's proposal were implemented, there would be more than 30,000 locations in the U.S. that could be used to deposit cash for the purpose of funding debit cards.

However, funding could also be provided by the private sector if implemented on a large scale to maintain ubiquity. The M-Pesa in Kenya provides a good example of an innovative payment instrument for the unbanked. Founded in 2007 and introduced by Safaricom mobile phone service provider, it provides a unique payment and money transfer service via mobile phones. ${ }^{7}$ In a country with mostly unbanked consumers, the real innovation was that M-Pesa tackled directly the funding problem via small kiosks that were spread out in remote villages. In these kiosks, MPesa users can exchange cash for mobile money and the other way around. There is no equivalent service in the U.S. because all mobile phone payment services rely on funding via credit cards, debit card, or bank accounts, hence cannot be used by consumers who do not have payment cards. $^{8}$

The remainder of this article simulates the effects of these policy proposals by computing consumer surplus assuming first that unbanked consumers gain access to debit cards (with funding options), and second assuming that the cost of obtaining these debit cards is subsidized. ${ }^{9}$

\subsection{How assessments are used}

Recall that in order to mitigate potential endogeneity problems, instead of using individual-specific assessments as independent variables, the simulations below use the weighted medians of cost, security, and convenience assessments as independent variables. These are displayed on the sixth column in Table 2. This simulation procedure assumes that the population weighted median values capture the "objective" cost and benefit values. It is important to emphasize that the scale of each assessment rating (1 to 5) has no effect on the simulated changes in consumer surplus. More precisely, the exact same changes occur even if we double the assessment ratings to range from 2

\footnotetext{
${ }^{7}$ See https:/ / www.vodafone.com/what-we-do/services/m-pesa.

${ }^{8}$ In the U.S., there are some bank-like services where consumers can fund payment cards with direct deposits, for example, Netspend https://www.netspend.com, Chime https://www.chimebank.com, and Walmart Blue Bird card https:/ / www.bluebird.com. The latter can also be funded with cash for free at any Walmart store.

${ }^{9}$ For similar counterfactual analyses of payments policy see Huynh et al. (2020) who estimate the effects of introducing central bank digital currency in Canada, and Shy (2020) who investigates the loss of consumer surplus assuming that all stores become cashless.
} 
to 10 (instead of 1 to 5) or any other linear transformation of these assessment ratings.

\subsection{Simulation 1: Providing debit card to unbanked consumers}

Suppose now that unbanked consumers gain access to debit cards (with funding options), so their set of payment methods becomes $\widehat{I}=\{$ cash, prepaid card, debit card $\}$ which is larger than the initial payment choice set $I=\{$ cash, prepaid card $\}$. Substituting the median assessment values from Table 2 into the estimated utility equation (3) yields a consumer's estimated utility level $V_{i}$ derived from each payment made with instrument $i$. Hence,

$$
V_{\text {Cash }}=5.608295, \quad V_{\text {Prepaid }}=3.610559, \quad V_{\text {Debit }}=5.60141, \text { and } V_{\text {Debit }}^{\text {Subsidized }}=6.600278 .
$$

The utility derived from paying debit $V_{\text {Debit }}$ is based on providing unbanked consumers access to debit cards. Just like $V_{\text {Cash }}$ and $V_{\text {Prepaid, }}$, it is based on the median assessment values displayed in Table 2 substituted into the estimated utility equation (3), where the median cost assessment

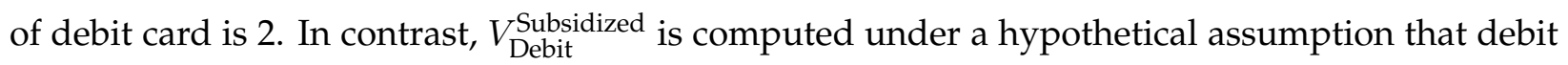
cards are subsidized which leads to a reduction in the assessment of cost from 2 to 1 . All other debit card assessments (security and convenience) were left at their median levels given in Table 2. That is, the utility derived from paying debit $V_{\text {Debit }}^{\text {Subsized }}$ corresponds to a cost subsidy given fixed security and convenience assessments.

Next, following Train (2009) (chapter 3, page 56), the per-payment rate of change in consumer surplus resulting from the hypothetical addition of a payment instrument (payment instrument $i=$ debit) is computed by ${ }^{10}$

$$
\frac{\Delta C S}{C S}=\frac{\mathrm{E}(C S)_{3 \mathrm{PI}}-\mathrm{E}(C S)_{2 \mathrm{PI}}}{\mathrm{E}(C S)_{2 \mathrm{PI}}}=\frac{\ln \left(\sum_{i \in \widehat{I}} e^{V_{i}}\right)-\ln \left(\sum_{i \in I} e^{V_{i}}\right)}{\ln \left(\sum_{i \in I} e^{V_{i}}\right)}
$$

\footnotetext{
${ }^{10}$ It should be emphasized that, for this purpose of this article, the terms consumer welfare, utility, and consumer surplus all refer to the net gain (benefit minus cost) consumers derive from the paying using a particular payment instrument. Here, the use of these three terms is substantially different from the widespread use of these terms to measure the benefits derived from consuming products or services that consumers purchase.
} 
where, subscript 3PI indicates the surplus with three payment instruments (cash, prepaid card, and debit card) after debit cards are added.

Two issues are worth noting about (5). First, individuals' marginal utility of income (which we do not know) are omitted from (5) because each marginal utility cancels out when expressed as a percentage change (instead of just a difference in consumer surplus). Second, the formulation (5) relies on the assumption that the estimated utilities of payment instruments $V_{i}$ for $i \in I$ do not change when the payment choice set expands from $I$ to $\widehat{I}$. This assumption implies that the assessments of debit card attributes (cost, security, and convenience) are independent of the assessments of cash and prepaid cards. This assumption is reasonable because respondents' assessments are ratings (not rankings) so each assessment can take any number between 1 to 5 independently of the numbers assigned to other payment instruments. From a technical perspective, (5) relies on the Property of Independence of Irrelevant Alternatives (IIA) in which “...exclusion [inclusion] of alternatives in [logit] estimation does not affect the consistency of the estimator," Train (2009) (chapter 3, page 49, [content in brackets was added]).

Expression (5) provides the formula for simulating the rate of change in consumer surplus resulting from making debit cards accessible to unbanked consumers. Substituting the computed values of $V_{i}$ from (4) into (5) yields

$$
\frac{\Delta C S}{C S}=10.96 \% \text { and } \quad \frac{\Delta C S^{S}}{C S}=21.21 \% .
$$

Thus, according to these simulations, providing unbanked consumers access to nonsubsidized debit cards will increases the welfare they derive from making a payment by 10.96 percent. In addition, if the cost of debit cards is subsided and reduced to the cost assessment level of cash, consumer welfare derived from making payments increases by 21.21 percent.

\subsection{Simulation 2: Subsidizing the cost of prepaid cards}

The difference between the benefits consumers derive from debit cards and prepaid card are blurred. Both payment methods must be prefunded. In the case of debit cards, card holders must maintain a sufficient balance in their bank account to cover all payments made with their debit cards. In the case of prepaid cards, these funds are loaded into a server that maintains the balance 
available on the card. In fact, some prepaid cards in the U.S. have the word "Debit" printed on the cards.

However, the major difference between debit cards and prepaid cards is that loading funds on prepaid cards is very costly to consumers, see Hayashi, Hanson, and Maniff (2015). Therefore, the simulation below examines a policy where prepaid cards are subsidized so that the median assessment cost of prepaid cards is lowered to that of cash which listed in Table 2.

The utility from paying with a prepaid card $V_{\text {Prepaid }}$ in expression (4) was computed under under the median assessment levels displayed in Table 2. Suppose now that instead of providing debit cards to unbanked consumers, the cost of prepaid is subsidized which leads to a reduction in the cost assessment from 3 to 1 . All other prepaid card assessments (security and convenience) were left at the median levels displayed in Table 2. Therefore, the set of payment methods $I=$ $\{$ cash, prepaid card $\}$ remains unchanged.

The utility consumers derive from paying with a prepaid card $V_{\text {Prepaid }}^{S}$ following a cost subsidy, holding the security and convenience assessments constant, is computed by substituting the median assessment values from Table 2 into the estimated utility equation (3), except that the cost assessment is now reduced from 3 to 1 . Hence, an unbanked consumer's estimated utility level $V_{i}$ derived from paying with instrument $i \in\{$ cash, prepaid card $\}$, previously given in (4), is now modified to

$$
V_{\text {Cash }}=5.608295, \quad \text { and } \quad V_{\text {Prepaid }}^{S}=5.608295 .
$$

Therefore, the cost subsidy to prepaid card uses increases the per-payment utility of prepaid cards from 3.61 to 5.60. Substituting the computed values of $V_{i}$ from (7) into (5) yields

$$
\frac{\Delta C S^{S}}{C S}=9.86 \%
$$

Thus, according to the simulations, a cost subsidy of prepaid cards will increase the per-payment consumer welfare by 9.86 percent. 


\subsection{Interpreting the simulation results}

Equations (6) and (8) display the simulated changes in consumer welfare associated with three policy proposals: providing unsubsidized or subsidized debit cards, or subsidizing prepaid cards. How should these numbers be interpreted?

As pointed out earlier, the profession lacks accounting standards for measuring consumer cost of using each payment method. The cost studies cited in footnote 3 provide inconsistent cost estimates, which make them unusable for the purpose of this research. Without cost studies, the simulation results cannot be interpreted in terms of dollar value. For that reason, the simulations rely on sample medians of consumes' assessments (attributed) of each payment methods. Consequently, this implies that the actual numbers given in equations (6) and (8) have only limited interpretative value.

However, a comparison of the three simulations (providing unsubsidized or subsidized debit cards or subsidizing prepaid cards) reveals something about the value unbanked consumers attach to these policies. More precisely, (6) can be decomposed into two welfare effects: First, providing a debit card to consumers who do not have debit cards simply enlarges the set of payment choices available to these consumers. Thus, the 10.96 percentage increase is due to an added payment option. Second, adding a cost subsidy to debit cards further increases consumer welfare to 20.21 percent (roughly doubled). This is a cost-reduction effect. Finally, this cost-reduction effect is similar to the consumer welfare gain displayed in (8) resulting from a cost subsidy for prepaid cards.

\section{Discussion and summary}

This article identifies strong correlations between household income and the variety of payment instruments available to consumers. The computations leading to Table 1 imply that 24.5 percent of respondents with household income not exceeding $\$ 20,000$ are unbanked and do not have credit or debit cards. This percentage drops to 5.9 percent for income between $\$ 20,000$ and $\$ 30,000$, and to 3.6 percent for household income between $\$ 30,000$ and $\$ 40,000$.

Using 2014 survey data, Cole and Greene (2017) examine similarities and differences among 
three groups of consumers: unbanked, underbanked, and fully banked. They show that consumers in the three groups have different demographic characteristics, income, and payment behaviors, and that unbanked and underbanked consumers are significantly more likely than fully banked consumers to own a general purpose reloadable prepaid card. According to FDIC (2018), 34 percent of unbanked U.S. households cite "Do not have enough money to keep in an account" as their main reason for not having a bank account. Also, 12.6 percent cite "Do not trust banks" as the main reason for not having an account, and 8.6 percent cite "Account fees too high" as their main reason. Other reasons include: “Account fees unpredictable," "ID, credit, or former bank account problems," "Banks do not offer needed products or services," “Inconvenient hours," and "Inconvenient locations."

Having a bank account is considered as one of several criteria for financial inclusion. The G20 group of countries measures financial inclusion in three dimensions: access to financial services, usage of financial services, and quality of the product and service delivery. ${ }^{11}$ However, these criteria are too general for the purpose of this article because the focus of this article is on access to payment instruments by low-income consumers and not on other financial services, such as borrowing. In this respect, BIS (2016) analyzes the payment aspects of financial inclusion and the measures that could be taken to address these issues. In particular, it makes the point that "a transaction account is an essential financial service in its own right and can also serve as a gateway to other financial services." BIS (2016) defines transaction accounts as "accounts (including e-money/prepaid accounts) held with banks or other authorized and/or regulated payment service providers (PSPs), which can be used to make and receive payments and to store value."

\section{References}

Alvarez, Fernando and David Argente. 2019. "Consumer Surplus of Alternative Payment Methods: Paying Uber with Cash." University of Chicago, Becker Friedman Institute for Economics Working Paper No. 2019-96.

Arango, Carlos, Kim Huynh, and Leonard Sabetti. 2015. “Consumer Payment Choice: Merchant Card Acceptance Versus Pricing Incentives." Journal of Banking and Finance 55:130-141.

\footnotetext{
${ }^{11}$ See, https://databank.worldbank.org/data/download/g20fidata/G20_Financial_Inclusion_Indicators.pdf.
} 
Baradaran, Mehrsa. 2015. How the Other Half Banks: Exclusion, Exploitation, and the Threat to Democracy. Harvard University Press.

BIS. 2016. "Payment Aspects of Financial Inclusion." Bank of International Settlements/World Bank Working Paper Series.

Borzekowski, Ron and Elizabeth Kiser. 2008. "The Choice at the Checkout: Quantifying Demand Across Payment Instruments." International Journal of Industrial Organization 26 (4):889-902.

Briglevics, Tamás and Scott Schuh. 2020. “This Is "What's in Your Wallet”... and Here's How You Use It." West Virginia University, Economics Faculty Working Papers Series no. 45.

Ching, Andrew and Fumiko Hayashi. 2010. "Payment Card Rewards Programs and Consumer Payment Choice." Journal of Banking and Finance 34 (8):1773-1787.

Cole, Allison and Claire Greene. 2017. "Financial Inclusion and Consumer Payment Choice." Journal of Financial Transformation 46:219-235.

FDIC. 2018. “2017 FDIC National Survey of Unbanked and Underbanked Households.” Federal Deposit Insurance Corporation.

Hayashi, Fumiko, Josh Hanson, and Jesse Maniff. 2015. "Driver of Choice? The Cost of Financial Products for Unbanked Consumers." Federal Reserve Bank of Kansas City Research Working Paper No. 15-15.

Hayashi, Fumiko and William Keeton. 2012. "Measuring the Costs of Retail Payment Methods." Federal Reserve Bank of Kansas City, Economic Review, Second Quarter.

Hayashi, Fumiko and Sabrina Minhas. 2018. "Who Are the Unbanked? Characteristics Beyond Income." Federal Reserve Bank of Kansas City, Economic Review, Second Quarter.

- 2020. "Credit and Debit Card Interchange Fees in Various Countries." Federal Reserve Bank of Kansas City.

Huynh, Kim, Jozef Molnar, Oleksandr Shcherbakov, and Qinghui Yu. 2020. "Demand for Payment Services and Consume Welfare: The Introduction of a Central Bank Digital Currency." Bank of Canada, Staff Working Paper 2020-7.

Klee, Elizabeth. 2008. "How People Pay: Evidence from Grocery Store Data." Journal of Monetary Economics 55 (3):526-541.

Kosse, Anneke, Heng Chen, Marie-Hélène Felt, Valéry Dongmo Jiongo, Kerry Nield, and Angelika Welte. 2017. "The Costs of Point-of-Sale Payments in Canada." Bank of Canada Staff Discussion Paper No. 2017-4. 
Koulayev, Sergei, Marc Rysman, Scott Schuh, and Joanna Stavins. 2016. “Explaining Adoption and Use of Payment Instruments by US consumers." The RAND Journal of Economics 47 (2):293-325.

Krüger, Malte and Franz Seitz. 2014. "Costs and Benefits of Cash and Cashless Payment Instruments: Overview and Initial Estimates." Study commissioned by the Deutsche Bundesbank.

Rogoff, Kenneth. 2016. The Curse of Cash. Princeton University Press.

Schmiedel, Heiko, Gergana Kostova, and Wiebe Ruttenberg. 2012. "The Social and Private Costs of Retail Payment Instruments: A European Perspective.” ECB Occasional Paper No. 137.

Shampine, Allan. 2012. "An Evaluation of the Social Costs of Payment Methods Literature." Available at SSRN 1984248.

Shy, Oz. 2020. “Cashless Stores and Cash Users.” Available at SSRN No. 3375690.

Train, Kenneth. 2009. Discrete Choice Methods with Simulation. Cambridge University Press, $2^{\text {nd }}$ ed.

Wakamori, Naoki and Angelika Welte. 2017. "Why Do Shoppers Use Cash? Evidence from Shopping Diary Data." Journal of Money, Credit and Banking 49 (1):115-169. 


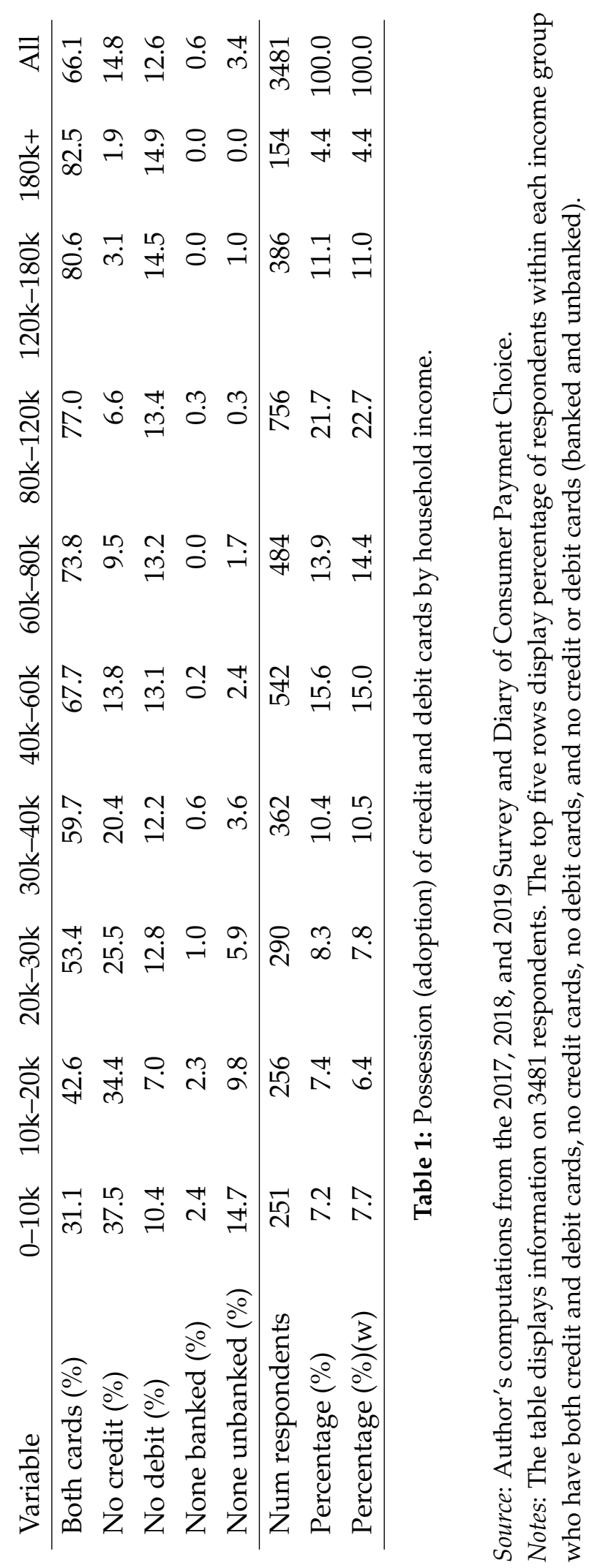




\begin{tabular}{rrrrrrrr} 
& $1(\%)$ & $2(\%)$ & $3(\%)$ & $4(\%)$ & $5(\%)$ & Median(w) & Average $(\mathrm{w})$ \\
\hline Cash cost assessment & 67.7 & 10.9 & 19.4 & 1.5 & 0.5 & 1.0 & 1.6 \\
Check cost assessment & 29.7 & 40.0 & 21.5 & 7.9 & 0.9 & 2.0 & 2.1 \\
Credit cost assessment & 20.8 & 17.5 & 16.9 & 31.5 & 13.2 & 3.0 & 3.0 \\
Debit cost assessment & 45.8 & 27.9 & 20.8 & 4.6 & 0.8 & 2.0 & 1.9 \\
Prepaid cost assessment & 21.8 & 27.4 & 33.6 & 14.7 & 2.5 & 3.0 & 2.5 \\
\hline Cash security assessment & 34.0 & 14.3 & 13.7 & 13.8 & 24.2 & 3.0 & 2.8 \\
Check security assessment & 8.1 & 32.7 & 20.5 & 31.2 & 7.6 & 3.0 & 3.0 \\
Credit security assessment & 9.7 & 23.4 & 12.4 & 38.1 & 16.4 & 4.0 & 3.2 \\
Debit security assessment & 10.8 & 30.3 & 14.3 & 34.3 & 10.4 & 3.0 & 3.0 \\
Prepaid security assessment & 17.0 & 22.3 & 27.0 & 22.7 & 11.1 & 3.0 & 2.9 \\
\hline Cash convenience assessment & 4.0 & 10.8 & 14.5 & 28.1 & 42.6 & 4.0 & 4.0 \\
Check convenience assessment & 8.2 & 25.5 & 22.1 & 30.7 & 13.5 & 3.0 & 3.1 \\
Credit convenience assessment & 2.7 & 1.8 & 6.7 & 27.7 & 61.1 & 5.0 & 4.4 \\
Debit convenience assessment & 2.3 & 2.3 & 8.6 & 30.5 & 56.3 & 5.0 & 4.4 \\
Prepaid convenience assessment & 5.8 & 15.2 & 25.9 & 30.2 & 22.9 & 4.0 & 3.5 \\
\hline
\end{tabular}

Table 2: Respondents' assessments of cost, security, and convenience of cash, checks, credit cards, debit cards, and prepaid cards.

Source: Author's computations from the 2017, 2018, and 2019 Survey and Diary of Consumer Payment Choice.

Notes: Table displays information on 3481 respondents. Cost is rated 1 (lowest cost) to 5 (highest cost, hence less desirable). Security and convenience are rated 1 (least desirable) to 5 (most desirable). (w) refers to weighted statistics to fit the adult U.S. population. 


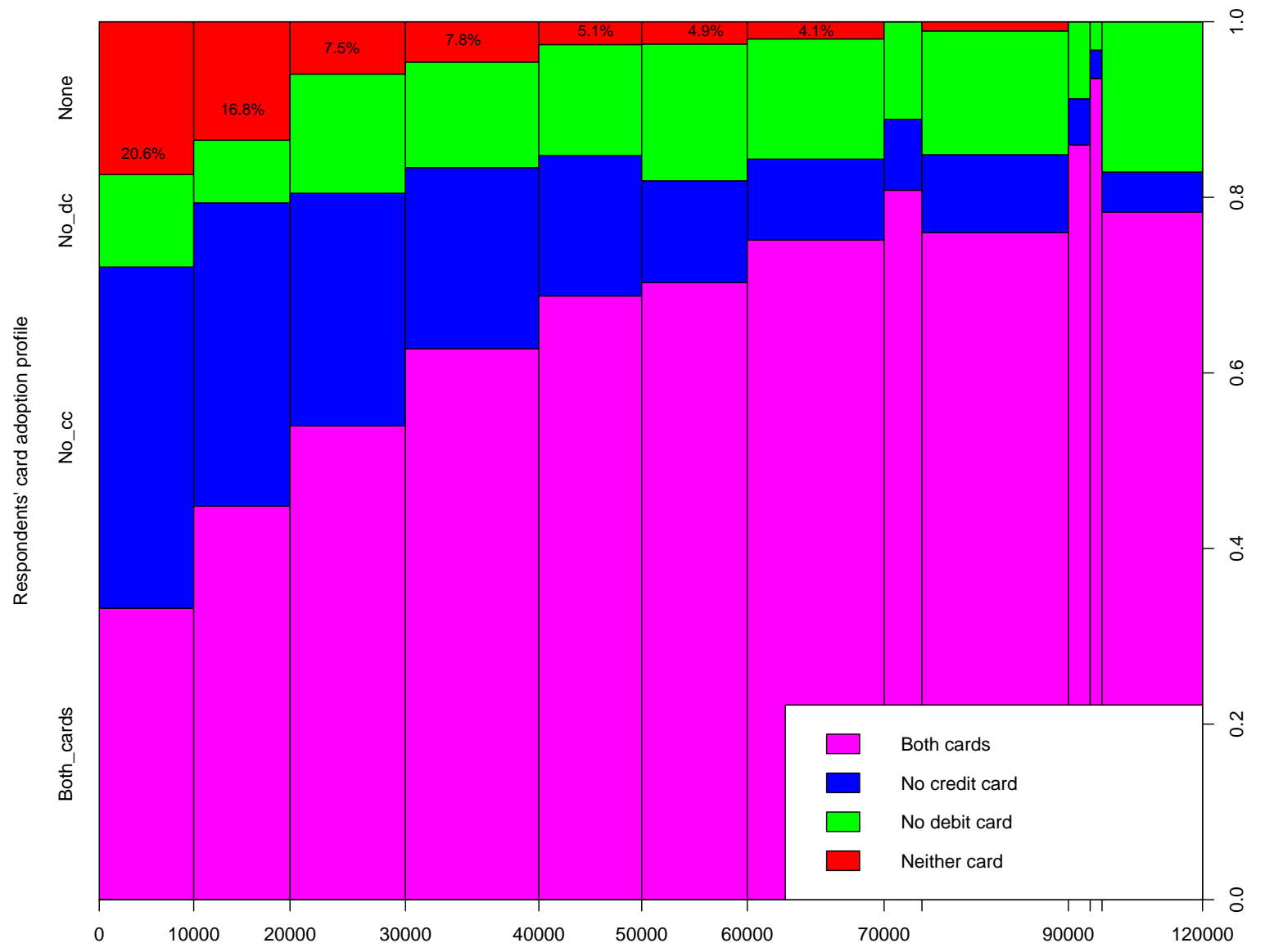

Figure 1: Respondents' possession of credit and debit cards by household income.

Source: Author's computations from the 2017, 2018, and 2019 Survey and Diary of Consumer Payment Choice.

Note: Based on 3039 (87.3 percent) of respondents with household income not exceeding \$120,000. 